ORIGINAL ARTICLE

\title{
Prenatal predictors of chronic lung disease in very preterm infants
}

\author{
D J Henderson-Smart, J L Hutchinson, D A Donoghue, N J Evans, J M Simpson, \\ I Wright, for the Australian and New Zealand Neonatal Network
}

Arch Dis Child Fetal Neonatal Ed 2006;91:F40-F45. doi: 10.1136/adc.2005.072264

\begin{abstract}
Objective: To identify prenatal risk factors for chronic lung disease (CLD) at 36 weeks postmenstrual age in very preterm infants.

Population: Data were collected prospectively as part of the ongoing audit of the Australian and New Zealand Neonatal Network (ANZNN) of all infants born at less than 32 weeks gestation admitted to all tertiary neonatal intensive care units in Australia and New Zealand. Methods: Prenatal factors up to 1 minute of age were examined in the subset of infants born at gestational ages 22-31 weeks during 1998-2001, and who survived to 36 weeks postmenstrual age ( $n=11453)$. Factors that were significantly associated with CLD at 36 weeks were entered into a multivariate logistic regression model.

Results: After adjustment, low gestational age was the dominant risk factor, with an approximate doubling of the odds with each week of decreasing gestational age from 31 to less than 25 weeks (trend $\mathrm{p}<0.0001$ ). Birth weight for gestational age also had a dose-response effect: the lower the birth weight for gestational age, the greater the risk, with infants below the third centile having 5.67 times greater odds of CLD than those between the 25th and 75th centile (trend $p<0.0001$ ). There was also a significantly increased risk for male infants (odds ratio 1.51 (95\% confidence interval 1.36 to 1.68), p<0.0001).

Conclusions: These population based data show that the prenatal factors low gestational age, low birth weight for gestational age, and male sex significantly predict the development of chronic respiratory insufficiency in very preterm infants and may assist clinical decision about delivery.
\end{abstract}

See end of article for authors' affiliations

Correspondence to: Professor HendersonSmart, Centre for Perinatal Health Services Research, University of Sydney, Sydney, NSW 2006, Australia; dhs@perinatal. usyd.edu.au

Accepted 22 July 2005 Published online first 30 August 2005

$\mathrm{V}$ ery preterm infants commonly have respiratory failure in the first week after birth. With respiratory support, most infants survive without subsequent respiratory failure. In some, respiratory failure continues beyond one month and even up to the term equivalent age and beyond. This chronic lung disease (CLD), also known as bronchopulmonary dysplasia, is common in infants of very low gestational age $(\mathrm{GA})$ or birth weight $(\mathrm{BW})^{1}$ and is associated with other morbidities including growth failure, abnormal neurodevelopment, ${ }^{2-4}$ delayed discharge from hospital, need for home oxygen support, ${ }^{5}$ and more frequent readmission to hospital in the first year of life. ${ }^{6}$ Most studies on causality have emphasised lung injury from the physical effects of intermittent positive pressure ventilation and toxicity from high concentrations of oxygen. ${ }^{57}$ Prenatal factors and very preterm birth at a critical period of structural lung development ${ }^{8}$ may also be important.

As a large proportion of very immature infants are still receiving assistance at 28 days of age, respiratory support later, at near term age, has been used as a better measure of lung morbidity. ${ }^{9}$ This paper examines the prenatal factors associated with development of CLD in a population based regional cohort of infants born at very low gestation (less than 32 weeks). The focus is on variables that affect the infants' condition before they reach the neonatal intensive care unit (NICU), as this is the first phase of a project to examine variations in outcomes between NICUs and the model is to be used to adjust for case mix differences in risk of CLD between units.

\section{METHODS}

The cohort consists of consecutive liveborn infants of 2231 weeks gestation admitted in the first 28 days of life to the
25 tertiary NICUs in Australia and New Zealand's perinatal hospitals. These units are part of the Australian and New Zealand Neonatal Network (ANZNN), the members of which have prospectively collected a data set using agreed definitions since 1995. ${ }^{10}$ Based on data for the whole of New Zealand which are collected by ANZNN, ${ }^{11}$ and state maternity databases of all births in Australia, the cohort used here represents about $92 \%$ of all live births at less than 32 weeks and $99 \%$ of infants of that gestational age who develop CLD in the two countries. The predictive model was developed on babies born during the calendar years 1998 and 1999, then validated using a similar cohort from 2000 and 2001. Infants with lethal congenital malformations or hydrops were excluded. Analysis involved the 21 ANZNN variables covering the prenatal period and up to one minute after birth.

GA is expressed in completed weeks assessed on the basis of an obstetric ultrasound before 20 weeks, the first day of the last menstrual period, or clinical assessment of the infant. ${ }^{10} \mathrm{GA}$ was analysed in weekly increments from 25 to the reference group at 31 weeks, with infants born at less than 25 weeks grouped together. Birth weight for gestational age (BW for GA) centile groups were derived from the Australian national birth weight centile charts for infants of each sex. ${ }^{12} \mathrm{BW}$ for GA centile was divided into categories as follows $\geqslant 75$ th, 25 th-74th (reference group), 10th-24th, 3rd-9th, $<3$ rd to test for trend using the Mantel-Haenszel test. Symmetry around the reference category with divisions at the 90th and 97th centiles was explored, but these were collapsed into one large for GA ( $\geqslant 75$ th) centile grouping because they had similar parameter estimates.

Abbreviations: ANZNN, Australian and New Zealand Neonatal Network; CLD, chronic lung disease; IUGR, intrauterine growth restriction; NICU, neonatal intensive care unit; ROC, receiver operating characteristics 
CLD is defined as the use of any respiratory support including supplemental oxygen or any form of assisted ventilation, given for a chronic pulmonary disorder at 36 weeks postmenstrual age. Maternal ethnicity is defined by self report. Maternal age group compared teenagers and mothers over 34 with the other mothers. Maternal hypertension in pregnancy included all types, without information on drug treatment. Suspected intrauterine growth restriction (IUGR) is based on serial obstetric ultrasounds at any time. Babies were defined as being outborn if they were not born in the perinatal centre of registration. No information on chorioamnionitis was available.

Significant variables at $\mathrm{p}<0.05$ on univariate analysis were entered into a multivariate logistic regression model, and the least significant variable was removed sequentially. Variables were retained in the model if they were significant at $p<0.01$ and were not collinear with other variables. The fit of the model was checked using Hosmer and Lemeshow's goodness of fit statistic, ${ }^{13}$ with the additional verification that models were not over-fitted (indicated by very high $\mathrm{p}$ values). The discriminatory ability of the model was assessed using the area under the receiver operating characteristics (ROC) curve. Logistic regression diagnostics were also used to identify potential covariate patterns that were poorly fitted or highly influential. Analyses were performed using SAS statistical software, version 8.2 (SAS Institute, Cary, North Carolina, USA). Results are expressed as odds ratios (OR) with 95\% confidence interval (CI) in parentheses. Ethical approval for this study was given by the Royal Prince Alfred Hospital Human Ethics Review Committee and by the administering institution, the University of Sydney.

To compare our results with those published by others, we undertook a systematic search of Medline (1966-November 2004) to identify similar population based studies of very preterm infants that examined prenatal risk factors for CLD at 36 weeks postmenstrual age using GA to define the cohort. The population base criterion is chosen to minimise selection or referral bias in hospital based studies, and the use of GA rather than birth weight was chosen to avoid GA bias. ${ }^{14}$

\section{RESULTS}

There were 6249 infants born at 22-31 weeks GA in 1998 and 1999 and admitted to the NICUs of the ANZNN. Of these, 647 died before 36 weeks postmenstrual age, and for three the outcome CLD status was missing. The remaining 5599 infants had a median GA of 29 weeks with an interquartile range (IQR) of 27-30 weeks. The median birth weight was $1235 \mathrm{~g}$
(IQR 960-1505). The rate of CLD in this group was 22\% ( $\mathrm{n}=$ 1235). The validation cohort of 5854 surviving infants born in 2000-2001 had a CLD rate of $25 \%$, median GA of 29 weeks (IQR 27-30), and birth weight of $1235 \mathrm{~g}$ (IQR 960-1510). The male to female ratio was similar in the two periods: 1.2:1 in 1998-1999 and 1.1:1 in 2000-2001.

Factors that were not significant on univariate analysis (table 1) were not included in multivariate analyses. Table 2 shows factors that were significantly associated with CLD. Previous perinatal death, hypertension in pregnancy (any form), antepartum haemorrhage, breech position at birth, and caesarean section before labour started were associated with an increased risk, but did not retain significance in multivariate analysis. Likewise, there was an unadjusted protective association for preterm prelabour rupture of membranes that did not persist in the adjusted model.

Despite their statistical significance in the multivariate analysis, a low Apgar score at one minute, maternal ethnicity, and suspected IUGR were excluded from the final model. Reasons for this included evidence of collinearity between GA and Apgar score at one minute and, to some extent, Apgar score represents an infant's initial respiratory performance. Ethnicity is a difficult factor to assess, and its exclusion was justified by the amount of missing data (9\%), the inherent problems of different indigenous populations in the two countries, and the difficulty of separating the effect of ethnicity from social factors, which were not measured. Suspected IUGR was rejected because it was collinear with BW for GA, is likely to be variably reported, and because BW for GA provides a range of categories rather than the dichotomous one of suspected IUGR.

Multivariate analysis retained the variables: GA group, BW for GA group, and male sex, which were significant at $\mathrm{p}<0.01$ after simultaneous adjustment (table 3). Low GA was the dominant risk factor for CLD (table 3). The risk of CLD increases progressively with decreasing GA (trend $\chi^{2}{ }_{1}=997$, $\mathrm{p}<0.0001)$ as indicated by the ORs, with the most preterm infants ( $\leqslant 24$ weeks) having 86 times the odds of those born at 31 weeks. A dose-response effect was also apparent for BW for GA (trend $\chi^{2}{ }_{1}=272, p<0.0001$ ), indicating that the lower the birth weight at each GA, the greater the risk of CLD. Male sex was associated with an increased risk of CLD (OR 1.42 ( $95 \%$ CI 1.22 to 1.65 ), $\chi_{1}^{2}=20.1, \mathrm{p}<0.0001$ ). Similar results were also found after analysis of the validation cohort of babies born in 2000-2001 and the two cohorts combined-that is, born 1998-2001; see ORs in column 2 of table 3 and column 3 of table 4 .

\begin{tabular}{|c|c|c|c|}
\hline Perinatal variable & $\begin{array}{l}\text { Unadjusted OR } \\
(95 \% \mathrm{CI})\end{array}$ & p Value & $\begin{array}{l}\text { Missing } \\
\text { data }\end{array}$ \\
\hline Maternal age & & 0.41 & 0 \\
\hline$\geqslant 35$ years & $1.07(0.92$ to 1.26$)$ & & \\
\hline $20-34$ years & 1.00 reference group & & \\
\hline$<20$ years & $0.91(0.73$ to 1.13$)$ & & \\
\hline Previous preterm birth & $1.02(0.85$ to 1.22$)$ & 0.85 & 672 \\
\hline Prolonged rupture of membranes ( $>24 \mathrm{~h}$ ) & $0.99(0.85$ to 1.16$)$ & 0.93 & 428 \\
\hline Preterm labour & $0.93(0.81$ to 1.06$)$ & 0.25 & 6 \\
\hline Maternal corticosteroids (any dose) & 1.19 ( 0.99 to 1.43 ) & 0.06 & 218 \\
\hline Fetal distress requiring intervention & $1.12(0.95$ to 1.32$)$ & 0.17 & 518 \\
\hline Plurality & & 1.00 & 0 \\
\hline Singleton & 1.00 reference group & & \\
\hline Multiple pregnancy & 1.00 ( 0.87 to 1.15$)$ & & \\
\hline Birth order & & 0.95 & 2 \\
\hline $\begin{array}{l}\text { Singleton or } 1 \text { st of multiple pregnancy } \\
2 \text { nd or higher of multiple pregnancy }\end{array}$ & $\begin{array}{l}1.00 \text { reference group } \\
1.00(0.86 \text { to } 1.15)\end{array}$ & & \\
\hline Outborn, transferred after birth & $1.11(0.91$ to 1.37$)$ & 0.31 & 0 \\
\hline
\end{tabular}


Table 2 Univariate analysis: perinatal variables significantly associated with chronic lung disease (CLD) 1998-1999

\begin{tabular}{|c|c|c|c|c|}
\hline Perinatal variable & CLD/total & $\begin{array}{l}\text { Unadjusted OR } \\
(95 \% \mathrm{Cl})\end{array}$ & p Value & $\begin{array}{l}\text { Missing } \\
\text { data }\end{array}$ \\
\hline Maternal ethnicity & & & 0.002 & 505 \\
\hline White & $955 / 4163(23 \%)$ & 1.00 reference group & & \\
\hline Asian & $71 / 331(21 \%)$ & $0.92(0.70$ to 1.20$)$ & & \\
\hline Indigenous Australian & $51 / 243(21 \%)$ & $0.89(0.65$ to 1.23$)$ & & \\
\hline Maori & $15 / 116(13 \%)$ & $0.50(0.29$ to 0.86$)$ & & \\
\hline Pacific Islander & $35 / 241(15 \%)$ & $0.57(0.40$ to 0.82$)$ & & \\
\hline Previous perinatal death & $89 / 316(28 \%)$ & $1.41(1.09$ to 1.82$)$ & 0.01 & 708 \\
\hline Hypertension in pregnancy (any) & $298 / 1224(24 \%)$ & $1.18(1.02$ to 1.37$)$ & 0.03 & 63 \\
\hline Antepartum haemorrhage & $315 / 1276(25 \%)$ & 1.21 ( 1.04 to 1.40$)$ & 0.01 & 483 \\
\hline Preterm prelabour ROM & $249 / 1283(19 \%)$ & $0.81(0.70$ to 0.95$)$ & 0.008 & 0 \\
\hline Suspected IUGR & $193 / 663(29 \%)$ & $1.56(1.30$ to 1.87$)$ & $<0.0001$ & 79 \\
\hline Gestational age & & & $<0.0001$ & 0 \\
\hline 31 weeks & $59 / 1343(4 \%)$ & 1.00 reference group & & \\
\hline 30 weeks & $83 / 1056(8 \%)$ & $1.86(1.32$ to 2.62$)$ & & \\
\hline 29 weeks & $141 / 916(15 \%)$ & 3.96 ( 2.88 to 5.43$)$ & & \\
\hline 28 weeks & $159 / 737(22 \%)$ & $5.99(4.37$ to 8.20$)$ & & \\
\hline 27 weeks & $202 / 554(36 \%)$ & $12.49(9.13$ to 17.08$)$ & & \\
\hline 26 weeks & $228 / 463(49 \%)$ & 21.11 ( 15.36 to 29.02$)$ & & \\
\hline 25 weeks & $193 / 300(64 \%)$ & 39.25 ( 27.60 to 55.81$)$ & & \\
\hline$\leqslant 24$ weeks & $170 / 230(74 \%)$ & 61.65 ( 41.60 to 91.36$)$ & & \\
\hline Weight for gestational age & & & $<0.0001$ & 0 \\
\hline$\geqslant 75 \mathrm{th}^{*}$ & $173 / 1256(14 \%)$ & $0.65(0.54$ to 0.79$)$ & & \\
\hline 25 th-74th & $575 / 2930(20 \%)$ & 1.00 reference group & & \\
\hline 10 th-24th & $257 / 864(30 \%)$ & $1.73(1.46$ to 2.06$)$ & & \\
\hline $3 r d-9$ th & $146 / 376(39 \%)$ & $2.60(2.07$ to 3.26$)$ & & \\
\hline$<3$ rd & $84 / 173(49 \%)$ & 3.87 ( 2.83 to 5.28$)$ & & \\
\hline Sex & & & $<0.0001$ & 0 \\
\hline Female & $497 / 2526(20 \%)$ & 1.00 reference group & & \\
\hline Male & $738 / 3073(24 \%)$ & $1.28(1.14$ to 1.47$)$ & & \\
\hline Presentation & & & $<0.0001$ & 632 \\
\hline Cephalic & $667 / 3314(20 \%)$ & 1.00 reference group & & \\
\hline Breech & $354 / 1390(25 \%)$ & $1.36(1.17$ to 1.57$)$ & & \\
\hline Other & $75 / 263(29 \%)$ & $1.58(1.20$ to 2.10$)$ & & \\
\hline Delivery & & & 0.01 & 156 \\
\hline Vaginal birth & $476 / 2219$ (21\%) & 1.00 reference group & & \\
\hline Caesarean in labour & $273 / 1358$ (20\%) & 0.92 ( 0.78 to 1.09 ) & & \\
\hline Caesarean no labour & $454 / 1866(24 \%)$ & $1.18(1.02$ to 1.36$)$ & & \\
\hline Apgar at $1 \mathrm{~min}<4$ & $357 / 978(37 \%)$ & $2.45(2.11$ to 2.85$)$ & $<0.0001$ & 0 \\
\hline
\end{tabular}

Table 3 Adjusted odds ratios for chronic lung disease (CLD) in the inception cohort (1998-1999) and the verification cohort (2000-2001)

\begin{tabular}{|c|c|c|}
\hline & $\begin{array}{l}\text { Adjusted OR 1998-1999 } \\
\text { cohort }(95 \% \mathrm{Cl})\end{array}$ & $\begin{array}{l}\text { Adjusted OR 2000-2001 } \\
\text { cohort (95\% CI) }\end{array}$ \\
\hline Size of cohort & 5599 & 5854 \\
\hline $\mathrm{CLD}(\mathrm{n}(\%))$ & $1235(22 \%)$ & $1475(25 \%)$ \\
\hline \multicolumn{3}{|l|}{ Predictor variable } \\
\hline \multicolumn{3}{|l|}{ Gestational age } \\
\hline 31 weeks & 1.00 reference group & 1.00 reference group \\
\hline 30 weeks & $2.05(1.44$ to 2.91$)$ & $1.66(1.21$ to 2.26$)$ \\
\hline 29 weeks & 4.25 ( 3.07 to 5.88 ) & 3.26 ( 2.43 to 4.39 ) \\
\hline 28 weeks & $7.59(5.49$ to 10.51$)$ & $6.56(4.95$ to 8.70$)$ \\
\hline 27 weeks & $15.58(11.26$ to 21.57$)$ & $13.55(10.16$ to 18.06$)$ \\
\hline 26 weeks & $25.37(18.22$ to 35.33$)$ & $22.96(16.95$ to 31.11$)$ \\
\hline 25 weeks & $56.14(38.86$ to 81.10$)$ & 52.22 ( 37.03 to 73.64$)$ \\
\hline$\leqslant 24$ weeks & $85.70(57.00$ to 128.9$)$ & 142.4 ( 93.14 to 217.7 ) \\
\hline \multicolumn{3}{|c|}{ Weight for gestational age } \\
\hline$\geqslant 75 \mathrm{th}^{*}$ & $0.54(0.44$ to 0.67$)$ & $0.64(0.53$ to 0.71$)$ \\
\hline 25 th-74th & 1.00 reference group & 1.00 reference group \\
\hline 10 th-24th & $2.05(1.67$ to 2.51$)$ & $1.82(1.49$ to 2.23$)$ \\
\hline 3 rd-9th & 4.01 ( 3.06 to 5.24$)$ & 2.87 ( 2.21 to 3.75$)$ \\
\hline$<3$ rd & $6.25(4.29$ to 9.11$)$ & 5.27 ( 3.43 to 8.09 ) \\
\hline Male sex & $1.42(1.22$ to 1.65$)$ & $1.63(1.41$ to 1.89$)$ \\
\hline
\end{tabular}




\begin{tabular}{|c|c|c|c|}
\hline Predictor variable & $\begin{array}{l}\text { Parameter } \\
\text { estimate }\end{array}$ & $\begin{array}{l}\text { Standard } \\
\text { error }\end{array}$ & Adjusted OR (95\% Cl) \\
\hline Intercept & -3.4667 & 0.1008 & \\
\hline \multicolumn{4}{|l|}{ Gestational age } \\
\hline 31 weeks & 0 & & 1.00 reference group \\
\hline 30 weeks & 0.5972 & 0.1190 & $1.82(1.44$ to 2.29$)$ \\
\hline 29 weeks & 1.2996 & 0.1111 & $3.67(2.95$ to 4.56$)$ \\
\hline 28 weeks & 1.9475 & 0.1085 & 7.01 ( 5.67 to 8.67 ) \\
\hline 27 weeks & 2.6616 & 0.1096 & $14.32(11.55$ to 17.75$)$ \\
\hline 26 weeks & 3.1625 & 0.1136 & 23.63 ( 18.91 to 29.53 ) \\
\hline 25 weeks & 3.9639 & 0.1273 & 52.66 ( 41.04 to 67.58 ) \\
\hline$\leqslant 24$ weeks & 4.6643 & 0.1467 & 106.1 ( 79.58 to 141.4$)$ \\
\hline \multicolumn{4}{|c|}{ BW for GA (centile grouping) } \\
\hline$\geqslant 75$ th & -0.5285 & 0.0731 & $0.59(0.51$ to 0.68$)$ \\
\hline 25 th -74 th & 0 & & 1.00 reference group \\
\hline 10 th -24 th & 0.6503 & 0.0734 & $1.92(1.66$ to 2.21$)$ \\
\hline $3 \mathrm{rd}-9$ th & 1.2133 & 0.0961 & 3.37 ( 2.79 to 4.06 ) \\
\hline$<3 \mathrm{rd}$ & 1.7351 & 0.1438 & 5.67 ( 4.28 to 7.52 ) \\
\hline \multicolumn{4}{|l|}{ Sex } \\
\hline Female & 0 & & 1.00 reference group \\
\hline Male & 0.4144 & 0.0539 & $1.51(1.36$ to 1.68$)$ \\
\hline
\end{tabular}

To investigate the possible effect of measuring GA in completed weeks rather than days, a subgroup of 1892 infants who had documented expected dates of delivery and thus gestation in weeks and days was examined. No trend in the proportion of infants with CLD across days of the week was found when data on days of the week were pooled across GAs in whole weeks (trend $\chi_{1}^{2}=1.7, \mathrm{p}=0.20$ ).

The predictive model (cohort 1998-1999, table 3) yields an area under the ROC curve of 0.84, indicating excellent discrimination, and the Hosmer and Lemeshow test statistic indicates a good fit $(\mathrm{p}=0.33)$. The temporal stability also validates well for the 2000-2001 cohort, with excellent discrimination (area under ROC curve $=0.84$ ) and goodness of fit ( $p=0.27$ ). The regression diagnostics supported the summary validation measures of goodness of fit and did not reveal any highly influential subjects. The temporal validation gives justification to the combined results (1998-2001), with 11453 infants included, 24\% rate of CLD, the same area under the ROC curve, and similar goodness of fit $(\mathrm{p}=0.32)$. The larger cohort yields more precision, as evidenced by the narrower confidence intervals (column 2 of table 4 ).

Figure 1 shows the effect of BW for GA centile on CLD at each GA. This indicates that the effect of BW for GA may vary somewhat by GA, although the interaction term is not significant $(p=0.36)$. For example, all infants below the 75th BW for GA centile have similarly high rates of CLD at $\leqslant 24$ weeks GA, whereas all those at or above the 10th centile have similarly low rates at 31 weeks, and a dose-response effect is clearest in those at 25-29 weeks.

\section{DISCUSSION}

Low GA, lower BW for GA, and male sex are independent prenatal risk factors for CLD. Low GA at birth is the strongest risk factor, with an approximate doubling of the odds with each week that GA decreases. This strong "dose-response" relation has been a consistent finding in other studies. ${ }^{16-18}$ This is biologically plausible as the GA range covered is a critical period in structural lung development. ${ }^{8}$ An important stimulus to lung growth in utero is thought to come from distension of the lung with fluid to above its resting volume, ${ }^{19}$ and this would be lost after birth.

Independent of this GA effect, lower birth weight at each GA is associated with a progressive increase in the risk of developing CLD in survivors. Compared with the referent BW for GA in the 25th-75th centile range, there is almost a sixfold increase in odds in infants with a weight less than the 3rd centile, whereas in infants of higher weight, at or above the 75 th centile, it is protective. In another population based cohort study of infants defined by GA less than 32 weeks and surviving to 36 weeks postmenstrual age, there is a similar dose-response relation to $\mathrm{BW}$ for $\mathrm{GA}^{20}$ Compared with referent infants born with BW for GA between the 25th and 75th centiles, those with a BW for GA less than the 10th centile had an increase in the OR of developing CLD (OR 2.84 (95\% CI 2.01 to 4.00$)$ ), whereas infants with BW for GA above the 90th centile had a reduced risk (OR 0.41 (95\% CI 0.26 to 0.65$)$ ). Being small for GA was also found to be a risk factor for CLD in two French regional studies ${ }^{17} 21$ of very preterm infants who were admitted to a NICU.

Other studies have shown that, in infants at all gestations, those that are small for GA have more lung dysfunction in childhood..$^{22}{ }^{23}$ Size at birth is also predictive of lung disease in adults. ${ }^{24}$ Experimental studies in a range of animal species have shown a causal relation between reduced growth at a critical time of structural lung development and reduced lung size and function. This has been observed when fetal growth was reduced through undernutrition in rats, ${ }^{25}$ guinea pigs, ${ }^{26}$ and lambs, ${ }^{27}$ as well as when fetal growth was reduced through reduced placental function in sheep. ${ }^{28} 29$

A potential problem for our study was using GA measured in whole weeks. As GA is such a strong predictor of CLD, the risk may change from day zero to day six of any given week. In our study no such trend was found.

Male sex increases the odds of CLD by $51 \%$, and this finding is consistent with other reports. ${ }^{18}$ In some population based studies in which postnatal acute respiratory function has been included in models predicting CLD, male sex does not remain significant. ${ }^{17}{ }^{21}$ It is possible that sex acts by determining the risk of acute respiratory disease. The risk of mortality and morbidity has been consistently higher in male neonates, and the underlying mechanisms, including differential rates of maturation, have been discussed. ${ }^{30}$

The prenatal risk factors for CLD reported here also predict the severity of acute neonatal lung disease. ${ }^{31}$ The consequent treatments, such as mechanical ventilation and oxygen therapy, are associated with lung injury ${ }^{5}$ and may explain some of the increase in the risk of CLD. In studies reporting multivariate models for predicting CLD, which have included prenatal and neonatal factors such as acute respiratory failure, GA remains a significant predictor. ${ }^{17} 1821$ 


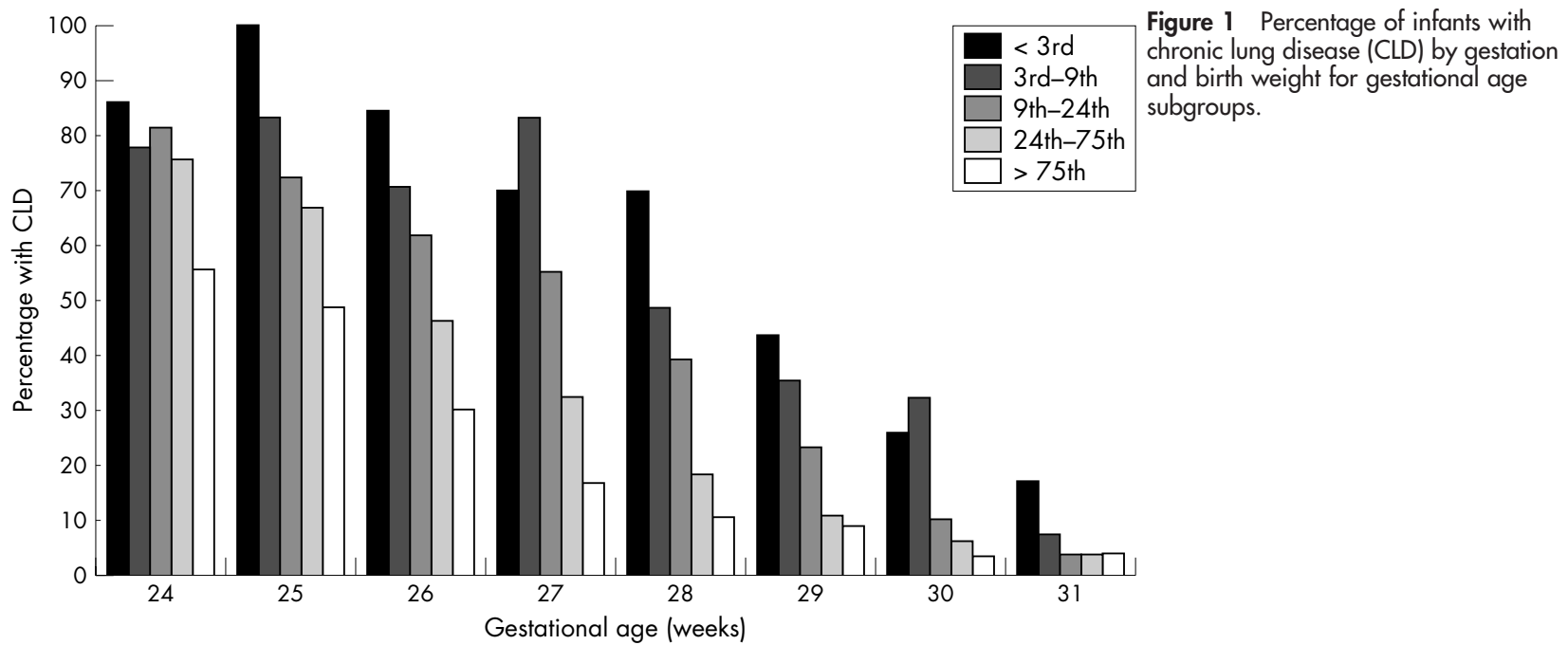

CLD is defined as receiving respiratory support and this was determined by individual clinical practice. Differences in clinical policies such as targeting higher or lower oxygen saturation have been shown to significantly affect the length of respiratory support with oxygen. ${ }^{32}$ However, this bias is between NICUs and is unlikely to affect infants in any systematic manner.

In very low birthweight infants admitted to a NICU in the ANZNN, GA, sex, and BW for GA were also found to be risk factors for death ${ }^{33}$ and retinopathy of prematurity, ${ }^{34}$ whereas GA and sex are risk factors for intraventricular haemorrhage. $^{35}$ Regardless of whether the risk factors found in the model here act partly through increased neonatal complications, they are the factors that are available before the birth of the infant. Obstetricians could use them to assess the risks of delivery and to inform parents about likely outcomes.

\section{ACKNOWLEDGEMENTS}

This research was supported by the National Health and Medical Research Council of Australia (grant 211088). Collaboration of members of the ANZNN (appendix) is gratefully acknowledged.

\section{Authors' affiliations}

D J Henderson-Smart, J L Hutchinson, D A Donoghue, Centre for Perinatal Health Services Research, University of Sydney, Sydney, Australia

N J Evans, Department of Neonatal Medicine, Royal Prince Alfred Hospital, Sydney

J M Simpson, School of Public Health, University of Sydney

I Wright, Department of Neonatal Medicine, John Hunter Children's Hospital, and Mothers and Babies Research Centre, University of Newcastle, Newcastle, Australia

Competing interests: none declared

\section{What is already known on this topic}

- Chronic lung disease in infants born very preterm is common, and the incidence increases with decreasing gestational age at birth and if the infant is small for gestational age. It is associated with the amount of intermittent positive pressure ventilation and level of oxygen therapy given to the infant

- Most of these results are based on a combination of prenatal and neonatal data from individual hospitals and on single cohorts

\section{APPENDIX}

\section{MEMBERS OF THE ANZNN ADVISORY COMMITTEE AND EXECUTIVE*}

Australia: Centre for Perinatal Health Services Research, NSW: David Henderson-Smart*. Flinders Medical Centre, SA: Peter Marshall. John Hunter Hospital, NSW: Chris Wake. King Edward Memorial and Princess Margaret Hospitals, WA: Noel French, Ron Hagan and Karen Simmer. Launceston General Hospital, Tas: Chris Bailey. Liverpool Health Service, NSW: Robert Guaran. Mater Mother's Hospital, Qld: David Tudehope. Mercy Hospital for Women, Vic: Andrew Watkins. Monash Medical Centre, Vic: Kaye Bawden*, Andrew Ramsden, Victor Yu. National Perinatal Statistics Unit, NSW: Paul Lancaster*. Nepean Hospital, NSW: Lyn Downe. Newborn Emergency Transport Service (Vic): Michael Stewart. NSW Newborn \& Paediatric Emergency Transport Service: Andrew Berry. Perinatal Research Centre, Qld: Paul Colditz. Royal Children's Hospital, Vic: Linda Johnstone, Peter McDougall. Royal Darwin Hospital, NT: Charles Kilburn. Royal Hobart Hospital, Tas: Peter Dargaville. Royal Hospital for Women, NSW: Kei Lui. Royal North Shore Hospital, NSW: Jennifer Bowen. Royal Prince Alfred Hospital, NSW: Nick Evans Royal Women's Hospital, Qld: David Cartwright*. Royal Women's Hospital, Vic: Colin Morley, Neil Roy. Sydney Children's Hospital, NSW: Barry Duffy. The Canberra Hospital, ACT: Graham Reynolds. The Children's Hospital at Westmead, NSW: Robert Halliday. The Townsville Hospital, Qld: John

\section{What this study adds}

- This study used prenatal data available for use in prognostication by the time of birth from large population based cohorts in two countries. The model was developed on a two year cohort and evaluated for stability on the cohort from the subsequent two years, thus increasing its validity

- The results confirm the large effect of low gestational age at birth and indicate the increased risk in male infants. Of particular note is the dose-response relation between lower birth weight for gestational age based on five measures across the whole range of birth weight 
Whitehall. Western Australia Neonatal Transport Service: Jenni Sokol. Westmead Hospital, NSW: William TarnowMordi. Women's \& Children's Hospital, SA: Ross Haslam. Deborah Donoghue is the ANZNN coordinator.

New Zealand: Christchurch Women's Hospital: Nicola Austin. Christchurch School of Medicine: Brian Darlow* Dunedin Hospital: Roland Broadbent. Gisborne Hospital: Graeme Lear. Hastings Hospital: Jenny Corban. Hutt Hospital: Robyn Shaw. Middlemore Hospital: Lindsay Mildenhall. National Women's Hospital: Carl Kuschel. Nelson Hospital: Peter McIlroy. Palmerston North Hospital Jeff Brown. Rotorua Hospital: Stephen Bradley. Southland Hospital: Paul Tomlinson. Taranaki Hospital: John Doran*. Tauranga Hospital: Hugh Lees. Timaru Hospital: Philip Morrison. University of Auckland: Jane Harding. Waikato Hospital: David Bourchier. Wairau Hospital: Ken Dawson. Wanganui Hospital: Neil MacKenzie. Wellington Women's Hospital: Vaughan Richardson. Whakatane Hospital: Chris Moyes. Whangarei Hospital: Peter Jankowitz.

\section{REFERENCES}

1 Stevenson DK, Wright LL, Lemons JA, et al. Very low birth weight outcomes of the National Institute of Child Health and Human Development Neonatal Research Network, January 1993 through December 1994. Am J Obstet Gynecol 1998;179:1632-9.

2 Sauve RS, Singhal N. Long-term morbidity of infants with bronchopulmonary dysplasia. Pediatrics 1985:76:725-33.

3 Skidmore MD, Rivers A, Hack M. Increased risk of cerebral palsy among very low-birthweight infants with chronic lung disease. Dev Med Child Neurol 1990;32:325-32.

4 Vohr BR, Coll CG, Lobato D, et al. Neurodevelopmental and medical status of low-birthweight survivors of bronchopulmonary dysplasia at 10 to 12 years of age. Dev Med Child Neurol 1991;33:690-7.

5 Jobe AH, Bancalari E. Bronchopulmonary dysplasia. Am J Respir Crit Care Med 2001;163:1723-9.

6 Chye JK, Gray PH. Rehospitalization and growth of infants with bronchopulmonary dysplasia: a matched control study. J Paediatr Child Health 1995;31:105-11

7 Bancalari E, Abdenour GE, Feller R, et al. Bronchopulmonary dysplasia: clinical presentation. J Pediatr 1979;95:819-23.

8 Burri PH. Fetal and postnatal development of the lung. Annu Rev Physiol 1984;46:617-28.

9 Shennan AT, Dunn MS, Ohlsson A, et al. Abnormal pulmonary outcomes in premature infants: prediction from oxygen requirement in the neonatal period. Pediatrics 1988;82:527-32.

10 Donoghue DA. Report of the Australian and New Zealand Neonatal Network 2002. Sydney: ANZNN, 2004

11 Darlow BA, Cust AE, Donoghue DA. Improved outcomes for very low birthweight infants: evidence from New Zealand national population based data. Arch Dis Child Fetal Neonatal Ed 2003;88:F23-8

12 Roberts CL, Lancaster PA. Australian national birth weight percentiles by gestational age. Med J Aust 1996;170:114-18.
13 Hosmer DW, Lemeshow S. Applied logistic regression. New York: John Wiley and sons, 2000.

14 Arnold CC, Kramer MS, Hobbs CA, et al. Very low birth weight: a problematic cohort for epidemiologic studies of very small or immature neonates. Am J Epidemiol 1991;134:604-13.

15 Lapeyre D, Klosowski S, Liska A, et al. Very preterm infant ( $<32$ weeks) vs very low birth weight newborns (1500 grammes): comparison of two cohorts. Arch Pediatr 2004;11:412-16.

16 Henderson-Smart, DJ. Postnatal consequences of chronic intrauterine compromise. Reprod Fertil Dev 1995;7:559-65.

17 Egreteau L, Pauchard JY, Semama DS, et al. Chronic oxygen dependency in infants born at less than 32 weeks' gestation: incidence and risk factors. Pediatrics 2001;108:E26.

18 Costeloe K, Hennessy E, Gibson AT, et al. The EPICure study: outcomes to discharge from hospital for infants born at the threshold of viability. Pediatrics 2000;106:659-71.

19 Harding R. Hooper SB. Regulation of lung expansion and lung growth before birth. J Appl Physiol 1996:81:209-24.

20 Lal MK, Manktelow BN, Draper ES, et al. Chronic lung disease of prematurity and intrauterine growth retardation: a population-based study. Pediatrics 2003; 11 1:483-487

21 Truffert $P$, Mailard F, Burguet $A$, et al. BPD and $C L D$ in very preterm infants: incidence in relation to SGA. Pediatr Res 2002;52:797.

22 Rona RJ, Gulliford MC, Chinn S. Effects of prematurity and intrauterine growth on respiratory health and lung function in childhood. BMJ 1993;306:817-20.

23 Vik T, Vatten L, Markestad T, et al. Morbidity during the first year of life in small for gestational age infants. Arch Dis Child Fetal Neonatal Ed 1996;75:F33-7.

24 Barker DJP, Godfrey KM, Fall C, et al. Relation of birth weight and childhood respiratory infection to adult lung function and death from chronic obstructive airways disease. BMJ 1991;303:671-5.

25 Gaultier C. Malnutrition and lung growth. Pediatr Pulmonol 1991;10:278-86.

26 Lechner AJ. Perinatal age determines the severity of retarded lung development induced by starvation. Am Rev Respir Dis 1985;131:638-43.

27 Harding JE. Periconceptual nutrition determines the fetal growth response to acute maternal undernutrition in fetal sheep of late gestation. Perinat Neonat Med 1997:2:310-19.

28 Maloney JE, Bowes G, Brodecky V, et al. Function of the future respiratory system in the growth retarded fetal sheep. J Dev Physiol 1982;4:279-97.

29 Joyce BJ, Louey S, Davey MG, et al. Compromised respiratory function in postnatal lambs after placental insufficiency and intrauterine growth restriction. Pediatr Res 2001;50:641-9.

30 Ingemarsson I. Gender aspects of preterm birth. Br J Obstet Gynaecol 2003;110(suppl 20):34-8

31 Tyson JE, Kennedy K, Broyles S, et al. The small for gestational age infant: accelerated or delayed pulmonary maturation? Increased or decreased survival? Pediatrics 1995:95:534-8.

32 Askie LM, Henderson-Smart DJ, Irwig L, et al. Oxygen-saturation targets and outcomes in extremely preterm infants. N Engl J Med 2003;349:953-61.

33 Hutchinson J, Donoghue D, Henderson-Smart D, et al. Risk factors for death in very preterm babies of the Australian and New Zealand Neonatal Network. Proceedings of the Perinatal Society of Australia and New Zealand, Sydney, 2004.

34 Darlow BA, Hutchinson JL, Henderson-Smart DJ, et al. Prenatal risk factors for severe retinopathy of prematurity in very preterm infants of the Australian and New Zealand Neonatal Network (ANZNN). Pediatrics 2005;115:990-6.

35 Heuchan AM, Evans N, Henderson Smart DJ, et al. Perinatal risk factors for major intraventricular haemorrhage in the Australian and New Zealand Neonatal Network, 1995 to 1997. Arch Dis Child Fetal Neonatal Ed 2002;86:F86-90. 